\title{
The Role of Drought Stress on Aflatoxin Contamination in Groundnuts (Arachis hypogea L.) and Aspergillus flavus Population in the Soil
}

Chancy B. Sibakwe ${ }^{1}$, Trust Kasambara-Donga ${ }^{1}$, Samuel M. C. Njoroge ${ }^{2}$, W. A. B. Msuku ${ }^{1}$, Wezi G. Mhango ${ }^{1}$, Rick L. Brandenburg ${ }^{3}$, and D. L. Jordan ${ }^{4}$

1. Department of Crop and Soil Sciences, Lilongwe University of Agriculture and Natural Resources, Malawi

2. Plant pathology Section, International Crop Research Institute for the Semi-Arid Tropics-ICRISAT, Malawi

3. Department of Entomology, North Carolina State University, USA

4. Department of Crop and Soil Sciences, North Carolina State University, USA

\begin{abstract}
Aflatoxins are naturally occurring toxic chemical substances that are produced by fungal species called Aspergillus flavus. The toxic substances are secondary metabolites, which contaminate groundnut while growing in the field and also post-harvest. Drought stress is one of the factors that contribute to increased aflatoxin levels in groundnut during field production. This study was conducted in a screen house at ICRISAT-Chitedze Agricultural Research Station, Malawi to investigate the effects of drought on aflatoxin contamination and A.flavus population in the soil. Four drought stress levels; prolonged (4 weeks), min ( 3 weeks), mild (2 weeks) and no drought were imposed on five groundnut varieties at pod filling stage. Soil samples were collected from each plot four times; at planting, beginning of drought, end of drought and at harvest. Aflatoxin levels in groundnut grain samples were estimated by use of neogenstrips read with mobile assay tablet reader. Population densities of A.flavus in soil samples collected from the plots were estimated using serial dilutions plated on the selective media, modified dichloran Rose Bengal (MDRB) and quantify A.flavus within 3 days after incubation at $37^{\circ} \mathrm{C}$. The results showed that there were significant differences in aflatoxin contamination between drought stress levels $(\mathrm{p}=0.011)$. High aflatoxin contamination was observed under prolonged drought $(22.0 \mathrm{ppb})$ compared to and no drought treatment $(1.5 \mathrm{ppb})$. None of the varieties used in the study showed either resistance or susceptibility to aflatoxin contamination under drought or adequate soil moisture. The results also showed that there were significant differences in A.flavus population at drought period and harvesting time and the mean population of A.flavus in prolonged drought at end of stress and harvesting were 8511 and $6044 \mathrm{cfu} / \mathrm{g}$ of soil respectively. It was concluded that drought contribute to aflatoxin contamination in groundnut, and also increased the A.flavus population in soil and also at harvesting.
\end{abstract}

Key words: groundnut, aflatoxin, drought, A. Flavus, contamination, CFU

\section{Introduction}

Groundnut (Arachishypogaea) is one of the major important legumes grown in Malawi and the entire world. It is ranked 13th important food crop and also 4th important crop for oil production in the world [1]. Groundnut is used to improve human nutrition, soil

Corresponding author: Chancy B. Sibakwe, MSc Crop Protecteion, BSc Agriculture, research areas/interests: crop protection. E-mail: sibakwec@gmail.com. fertility and economic status of many people [2]. One of major challenges that affect groundnut production in Malawi as well as other countries is aflatoxin contamination. Aflatoxin are substances produced by fungus Aspergillus flavus and Aspergillus parasiticus as secondary metabolites and are known with negative effect on human health as well on economic wellbeing of individuals and nations at large [3]. They are also known to be carcinogenic, toxic, and 
immunosuppressive and cause death to both human and animals [3]. The contamination of groundnut by aflatoxin occurs during pre-harvest (in field) and post-harvest. Agricultural products such as groundnut are being denied at international market due to high levels of the aflatoxin contamination beyond the acceptable standard level. The acceptable level of aflatoxin by (European Union) EU and Malawi bureau of standards (MBS) is $4 \mathrm{ppb}$ while for World Health Organization (WHO) is $20 \mathrm{ppb}[4,5]$. One of the contributing factors to the contamination in groundnut during pre-harvest is drought. Drought is a deficit in precipitation which creates a deficit in soil moisture [6]. In this study, four levels of drought were imposed to test their effects on aflatoxin contamination on five groundnut varieties and also on populations of A.flavus. The drought levels assessed were i) prolonged, ii) minimal, iii) mild and iv) No-drought and these were induced at the pod filling stage of the crop. There are several ways in which drought contribute to aflatoxin contamination. Drought condition increases the A.flavus population as groundnut roots and pods during drought produce more sucrose which is the growth substrate of A.flavus hence increasing the risk of contamination [7]. Drought condition is associated with poor pod filling and development, this result into shrived seeds with small seed size and usually they have small cracks which allow easy penetration of A.flavus $[8,9]$. Drought stress increases susceptibility of plants to insects and diseases because it reduces the accumulation of phytoalexinsin plants hence increasing the risk of contamination [10, 11]. Much of the studies has been conducted on the effect of drought on aflatoxin contamination in groundnut. Drought stress can vary from mild to severe. However, no or little has been done to evaluate the effects of different drought levels on aflatoxin contamination and A.flavus population focusing at pod filling stage. Therefore, this study was conducted to quantify the aflatoxin contamination in the soil and groundnut at different drought durations at pod filling stage.

\section{Materials and Methods}

The experiment was conducted in a screenhouse from October 2015 to February 2016, at the International Crops Research Institute for the Semi-Arid Tropics (ICRISAT) Malawi, hosted at Chitedze Agricultural Research Station in Lilongwe district. The Agricultural Research Station lies at 1097 $\mathrm{m}$ above sea level 13⒌'S latitude and $33^{\circ} 38^{\prime} \mathrm{E}$ longitude.

\subsection{Treatments and Experimental Design}

The experiment had two factors which were drought at four levels and variety at five levels. The four levels of drought were imposed at pod filling. The four drought stress levels were; prolonged (4 weeks' drought), minimal (3 weeks' drought), mild (2 weeks' drought) and no drought (control). Normal Watering resumed in all treatment after the end of each drought period up to physiological maturity. The varieties included five Spanish varieties commonly grown in Malawi were JL24 (Kakoma) ${ }^{1}$, ICGV-SM99568 (Chitala), ICG 12991 (Baka), ICGV-SM99566 and ICGV-SM01514. These were selected because they are widely grown by most farmers in Malawi and also ICGV-SM99566 and ICGV-SM01514 are newly released varieties in Malawi.

The experiment was laid in $4 \times 5$ split plot block design replicated three times which means that there were 60 subplots. Replicates also acted as blocks. The drought acted as main plot while varieties acted as subplots. The main plot was $2 \mathrm{~m}$ long and $0.6 \mathrm{~m}$ wide, $\left(1.2 \mathrm{~m}^{2}\right)$ and sub plot was $0.6 \mathrm{~m}$ long and $0.4 \mathrm{~m}$ wide $\left(0.24 \mathrm{~m}^{2}\right)$. The whole subplot also acted as net plot where by the plants harvested from it were used for measurement of yield, aflatoxin level and seed size. Soil samples were collected four times at a depth of 0 to $10 \mathrm{~cm}$ and 3 sub-samples per sub plot; planting (zero days after planting (0 DAP), beginning of stress (58

\footnotetext{
${ }^{1}$ All the variety names in blankets and italics are local names of the varieties and are named after the places where they perform best.
} 
DAP), end of stress (86 DAP) and harvesting (111

DAP). Timber boxes were used as planting containers. They were filled with soils sourced from fields around Chitedze Research Station not previously used for growing groundnuts. Soil samples collected before planting were analyzed for nutrient status and A.flavus population while subsequent samples were analyzed for A flavu sonly.

\subsection{Estimation of Populations of A.flavus}

The populations of A.flavus in soil were estimated by enumerating (through plating) on selective medium called Modified Dichloran Rose Bengal (MDRB) as described by Horn B. and Dorner J. (1998) [12]. $3.3 \mathrm{~g}$ of soil was suspended in $9 \mathrm{ml}$ water agar $(0.2 \%$ agar $)$ and vortexed. Serial diluted up to $10^{-5}$ and then plated on $90 \mathrm{~mm}$ diameter Petri dishes with MDRB medium [13]. Petri-dishes were then incubated at $37^{\circ} \mathrm{C}$ for 3 days and bright yellow-green colonies were counted as Aspergilli colony with the Jenko dissecting microscope at $2 \mathrm{x}-10 \mathrm{x}$ magnification. Colony forming units (CFU) were computed using the following formula as documented by[14]

$$
\mathrm{CFU} / \mathrm{g} \text { of soil }=\mathrm{A} \times 10^{\mathrm{n}} / \mathrm{V}
$$

where $\mathrm{A}=$ number of colonies;

$10^{\mathrm{n}}=$ level of dilution at which the counting was carried out;

$\mathrm{V}=$ Volume of inoculum.

All harvested grain samples from each sub plot were sun dried (up to $\leq 7 \%$ moisture level), hand shelled and taken to the laboratory for aflatoxin estimation using neogen strips read with a mobile assay tablet reader ${ }^{2}$. The whole sample from the subplot was blended in a Waring Commercial blender and sieved $(0.5 \mathrm{~mm}$ sieve). From each blended sample, $10 \mathrm{~g}$ was weighed. Thirty $\mathrm{ml}$ of $65 \%$ ethanol was added to $10 \mathrm{~g}$ blended sample and blended further to homogenize the mixture. The mixture was shaken at $300 \mathrm{rpm}$ for 5 minutes using Gallenkamp Orbital Shaker and finally filtered into

\footnotetext{
2 The whole analysis based on the Protocol for Use of mReader Application Neogen Reveal Q+.
}

filter cup (conical flask) through Whatman filter paper. $100 \mu 1$ of the filtered liquid was pipetted into red sample cup $^{3}$ and then $500 \mu 1$ of dilutant was added and mixed by pipetting 3 times. $100 \mu 1$ was pipetted from red sample cup into transparent sample cup $^{4}$. The neogen test strip (arrow down) was inserted into the transparent sample cup and left for 6 minutes. Finally, after 6 minutes the strip was removed and placed in strip holder of mReader tablet for aflatoxin readings.

\section{Results and Discussion}

\subsection{Effect of Moisture Stress Levels on Aspergillus Flavus Populations in Soil}

Figure 1 shows population of A.flavus at different drought stress levels. The results show that) there was a decrease in populations of A.flavus towards the beginning of the drought stress at 58 DAP. However, there were no significant differences in populations of A.flavuat different drought stress levels. However, at the end of the drought stress at 82 DAP there were significant differences observed in A.flavus populations. The control (no drought) had significantly lower populations $(1,922 \mathrm{cfu} / \mathrm{g}$ of soil) mild drought followed second $(3,511 \mathrm{cfu} / \mathrm{g}$ of soil), while $\mathrm{min}$ drought $(7,556 \mathrm{cfu} / \mathrm{g}$ of soil) and prolonged drought $(8,511 \mathrm{cfu} / \mathrm{g}$ of soil $)$ had significantly higher populations $(\mathrm{P}=<0.001)$. It was also observed that there was an increase in populations of A.flavusin all the treatments except in plots under no drought where there was continuous decrease in populations. There was also a decrease in populations of A.flavus after the end of drought stress or at the resumption of irrigation or prior to harvesting time. The populations were higher than the preceding stages before the beginning of drought stress. High populations were attributed to the hot and dry conditions experienced in the month of October, these two factors favour A.flavus population buildup [15]. Aspergillus flavus populations decreased with time in all treatments until at the drought

\footnotetext{
${ }^{3}$ Small cup used d for mixing the sample and dilutant.

${ }^{4}$ Small cup used for inserting the test strip.
} 
induction stage, this was attributed to watering all plots with same watering interval and volume. This cooled the soil in all the plots and eventually decreased soil temperature, low temperature and presence of enough moisture in the soil affected the A.flavus populations
[16]. Results from other studies also show a similar trend that, A.flavus populations and aflatoxin contaminations are high during hot-dry season and a bit lower during the rainy season $[15,17]$.

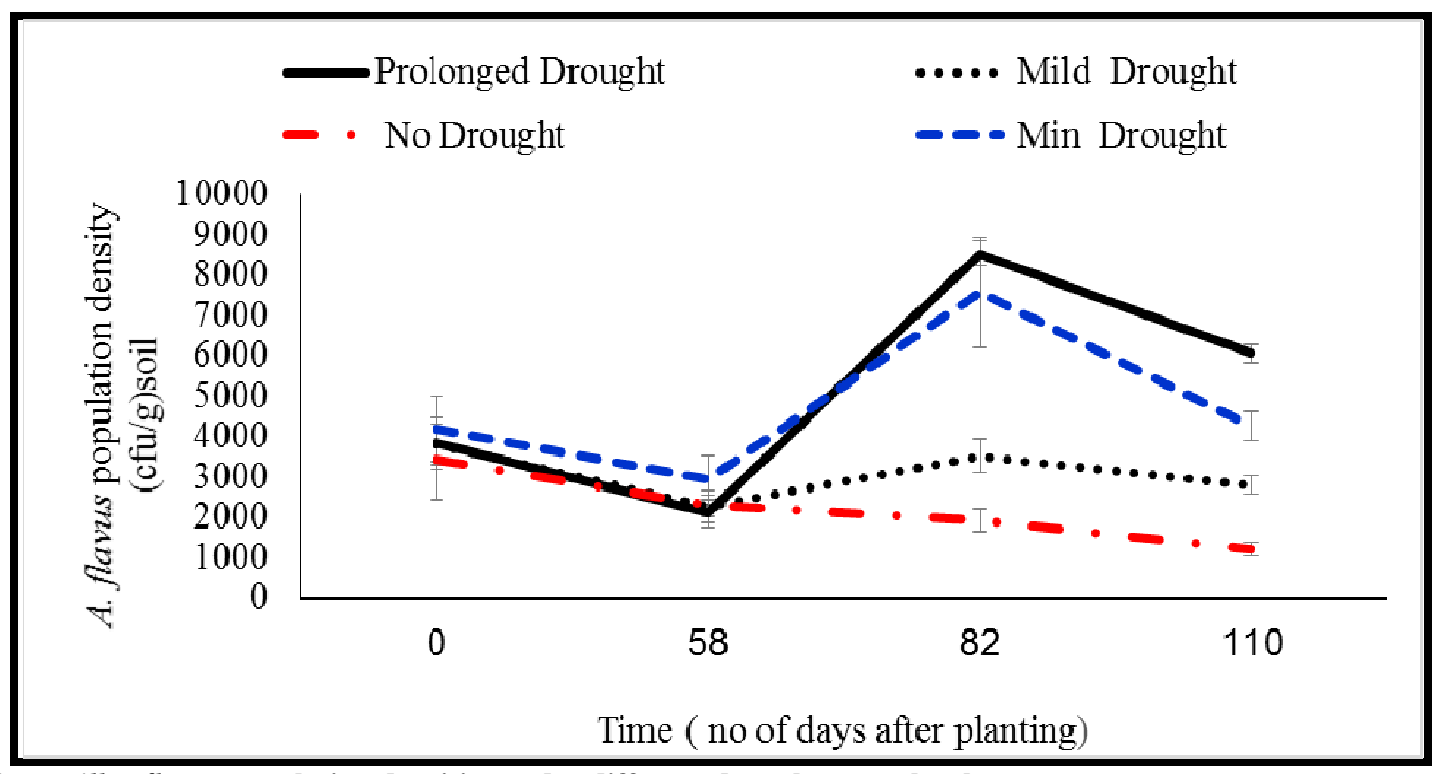

Fig. 1 Aspergillus flavus population densities under different drought stress levels.

\subsection{Effects of Drought on Aflatoxin B1 Contamination in Groundnuts}

The results in Table 1 show that there were significant differences $(P=0.011)$ in aflatoxin levels among drought stress levels. Highest levels were observed in prolonged drought $(22.0 \mathrm{ppb})$ while the lowest levels were observed in no drought (1.5 ppb). There were no significant differences $(P=0.492)$ in aflatoxin levels among varieties. Interaction between drought stress level and variety was also not significant $(\mathrm{P}=0.337)$. Exposing groundnut plants at pod filling stage (58 DAP) to drought has an effect on aflatoxin levels. The findings showed that the longer the period the plants are exposed to drought, the higher the risk of groundnut getting contaminated and this has been suggested [18-20]. Severe drought especially at critical stages of plant growth and development is associated with poor pod growth and development hence making them more susceptible to aflatoxin contamination [10]. Severe drought stress is linked with high exudation of sucrose by groundnuts pods and roots which support the growth of A.flavus hence increasing risk of high aflatoxin levels [7]. Another possible reason for high aflatoxin levels in prolonged drought; since there was poor pod filling and development, this resulted into shriveled seeds which tend to have small cracks hence increasing risk of being penetrated by A.flavus [8,9].

Low aflatoxin levels in no drought could be attributed to adequate soil moisture which is associated with high production of phytoalexins by plants, these boost the defensive mechanisms against pathogens [21]. In plants under normal soil moisture as discussed earlier, the pods and roots produce less sucrose hence less A.flavus colonies in soil as well as low aflatoxin levels $[7,22]$.

\subsection{Effects of Drought Duration Imposed at Pod Filling Stage on Aflatoxin Levels}

The results in Fig. 2 show that there was strong positive correlation between drought duration and aflatoxin levels as regression coefficient was high $\left(\mathrm{R}^{2}=\right.$ 

Aspergillus flavus Population in the Soil

0.8551). This means drought duration can be used to predict possible amount of aflatoxin levels in groundnut. Exposing groundnut plants to drought stress for long time increases aflatoxin as well as reduces yield [8, 23-25]. Therefore, irrigation should be used whenever there is drought in older to reduce the possibility of aflatoxin levels especially during rain fed farming.

Table 1 Aflatoxin B1 levels (ppb) in groundnut varieties under different drought levels.

\begin{tabular}{|c|c|c|c|c|c|c|}
\hline \multirow[t]{2}{*}{ Drought stress level } & \multicolumn{5}{|c|}{ Variety } & \multirow[b]{2}{*}{ Mean } \\
\hline & Baka & Chitala & Kakoma & ICGV-SM01514 & ICGV-SM99566 & \\
\hline None & 1.5 & 1.6 & 2.1 & 1.1 & 1.3 & $1.5^{\mathrm{a}}$ \\
\hline Mild & 3.0 & 3.7 & 7.1 & 3.9 & 4.0 & $4.3^{\mathrm{ab}}$ \\
\hline Min & 14.1 & 5.7 & 5.1 & 15.0 & 27.0 & $13.4^{\mathrm{bc}}$ \\
\hline Prolonged & 18.4 & 19.9 & 37.6 & 10.2 & 23.8 & $22.0^{\mathrm{cd}}$ \\
\hline Mean & 9.3 & 7.7 & 13.0 & 7.6 & 14.0 & \\
\hline Trt (Frob) & 0.011 & & & & & \\
\hline Variety (Frob) & 0.492 & & & & & \\
\hline Trt*variety (Frob) & 0.337 & & & & & \\
\hline Trt (LSD) 0.05 & 10.4 & & & & & \\
\hline
\end{tabular}

Means with different superscripts are significantly different $(\mathrm{p}<0.05)$; Trt $=$ Treatment; LSD $(0.05)$, Least significant difference at $5 \%$

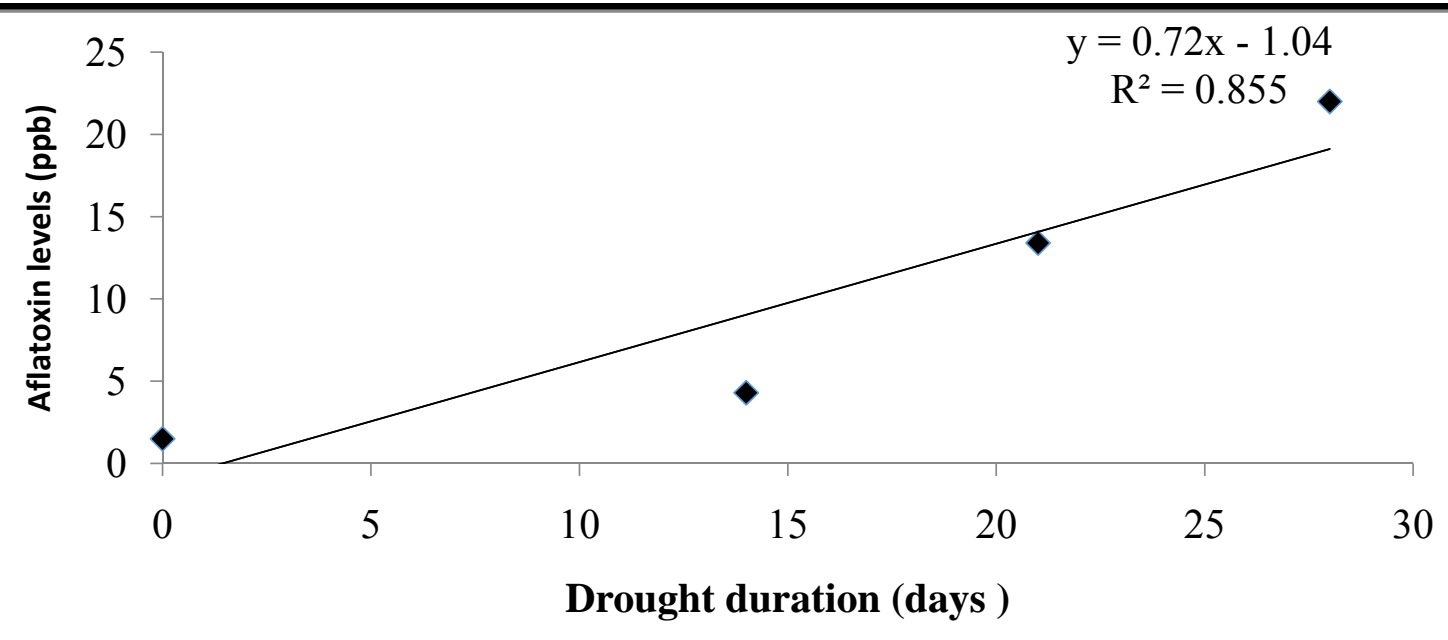

Fig. 2 Relationship between drought stress and aflatoxin levels.

\subsection{Correlation Coefficients of Aflatoxin Levels and Other Parameters}

In Table 2, Aflatoxin levels were positively correlated with drought duration $(P=<0.01, r=0.53)$, soil temperature $(P=<0.01, r=0.54)$ and CFU/g of soil $(P=0.05, r=0.45)$ and negatively correlated with seed size $(P=<0.01, r=0.50)$, yield $/$ ha $(P=<0.01, r$ $=0.51)$ and soil moisture $(P=<0.01, r=0.54)$. CFU $/ g$ of soil was positively correlated with drought duration $(P=<0.01, r=0.87)$, soil temperature $(P=<0.01, r=$ $0.75)$ and negatively correlated with seed size $(P=<$
$0.01, r=0.70) \mathrm{yield} / \mathrm{ha}(P=<0.01, r=0.75)$ and soil moisture $(P<0.01, r=0.67)$. Aflatoxin levels correlated with drought duration; lack of moisture provided a conducive environment for A.flavus to start producing aflatoxins hence increasing risk of high aflatoxin levels [10, 18, 24]. Aflatoxin levels also correlated with seed size, yield/ha, A.flavus population density, soil temperature and soil moisture. This means there is high possibility of high aflatoxin levels in groundnut samples with shrivelled. Small seed size is mostly associated with stresses such as drought, nutrients and other factors which affect growth and 
development of the pods [26-28]. The results also possibility of aflatoxin levels in groundnut. showed that yield/ha can also be used to predict the

Table 2 Correlation coefficients of different parameters.

\begin{tabular}{|l|c|c|c|c|c|c|c|}
\hline & Aflatoxin levels & Drought duration & CFU/g of soil & Seed size & Grain yield & Soil moisture & Soil temperature \\
\hline Aflatoxin levels & - & & & & & & \\
\hline $\begin{array}{l}\text { Drought } \\
\text { duration }\end{array}$ & $0.53^{* *}$ & - & & & & & \\
\hline CFU/g of soil & $0.45^{*}$ & $0.87^{* *}$ & - & & & & \\
\hline Seed size & $-0.50^{* *}$ & $-0.80^{* *}$ & $-0.70^{* *}$ & - & & & \\
\hline Grain yield & $-0.51^{* *}$ & $-0.88^{* *}$ & $-0.75^{* *}$ & $0.90^{* *}$ & - & & \\
\hline Soil moisture & $-0.54^{* *}$ & $-0.75^{* *}$ & $-0.67^{* *}$ & $0.67^{* *}$ & $0.69^{* *}$ & - & \\
\hline Soil temperature & $0.53^{* *}$ & $0.80^{* *}$ & $0.75^{* *}$ & $-0.69^{* *}$ & $-0.72^{* *}$ & $-0.76^{* *}$ & - \\
\hline
\end{tabular}

*, ** denotes significant at $\mathrm{P}<0.05$ and $\mathrm{P}<0.01$, respectively

\section{Conclusions}

The study on role of abiotic (drought) stress showed that there were high aflatoxin contamination levels in the prolonged drought and lower levels in no drought. This means that drought stress has effect on aflatoxin levels and the levels depend on the duration of the drought stress. The longer the drought duration the higher the aflatoxin levels should be expected. The study also revealed that, the varieties used played no role on aflatoxin levels in any of the drought levels, meaning that none of the varieties was more resistant or susceptible to aflatoxin levels under no drought or drought situation. Higher A.flavus populations were observed in prolonged drought and lower in no drought. There was also positive correlation between the A.flavus populations and aflatoxin levels. It was also noted that prolonged drought did not only increase aflatoxin levels but also contributed to low yields of groundnuts. It was recommended that whenever there is drought in groundnut fields, farmers should be advised to supplement water to crops using irrigation as it will minimize the risk of high aflatoxin levels, increase yield as well as reduce A.flavus population in the soil. This will be applicable to farmers who have access to water reservoirs for irrigation. Proper water requirement should be well calculated and available to plants depending on soil type and vegetative stage to avoid stress especially for irrigation farming as this will reduce aflatoxin levels. Farmers should also be practicing technologies that conserve water in soil to avoid moisture stress to groundnut plants. Some of the practices could be mulching and box or tie ridges to retain water in the soil.

\section{Acknowlegement}

This publication was made possible through support provided by the Office of Agriculture, Research and Policy, Bureau of Food Security, U.S. Agency for International Development, under the terms of Award No. AID-ECG-A-00-07-0001 to The University of Georgia as management entity for the U.S. Feed the Future Innovation Lab on Peanut Productivity and Mycotoxin Control.The opinions expressed herein are those of the author(s) and do not necessarily reflect the views of the U.S. Agency for International Development.

\section{References}

[1] V. B. Taru, I. Z. Kyagya and S. I. Mshelia, Profitability of groundnut production in Michika Local Government Area of Adamawa State, Nigeria,Journal of Agricultural Sciences 1 (2010) (1) 25-29.

[2] E. Monyo and C. Gowda (Eds.), Grain Legumes Strategies and Seed Roadmaps for Select Countries in Sub-Saharan Africa and South Asia: Tropical Legumes Il project Report, Patancheru, India: ICRISAT, 2014.

[3] K. Hell, P. Fandohan, R. Bandyopadhyay, S. Kiewnick, R. Sikora and P. J. Cotty, Pre- and postharvest management 
ofaflatoxin in maize: An African perspective, Management of Aflatoxin in Maize (2008) 219-229.

[4] E. S. Monyo, S. M. C. Njoroge, R. Coe, M. Osiru, F. Madinda, F. Waliyar and S. Anitha et al., Occurrence and distribution of aflatoxin contamination in groundnuts (Arachishypogaea $L$ ) and population density of Aflatoxigenic Aspergilli in Malawi, Crop Protection 42 (2012) 149-155, available online at: https://doi.org/10.1016/j.cropro.2012.07.004.

[5] Tsunehiro Otsuki and John S. Wilson, Saving two in a billion: A case study to quantify the trade effect of European food safety standards on African exports, Food Policy $26 \quad$ (2001) 495-514, doi: https://doi.org/10.1016/S0306-9192(01)00018-5.

[6] H. Mavi and G.Tupper, Agrometeorology: Principles and Applications of Climate Studies in Agriculture, London: CRC Press, 2004.

[7] J. Puntase, C. Senthong, S. Meechoui and K. T. Ingram, Effect of root exudates on drought and aflatoxin resistance of peanut genotypes, Journal of Chemical Information and Modeling $53 \quad$ (2004) (9) 1689-1699, doi: https://doi.org/10.1017/CBO9781107415324.004.

[8] F. Hamidou, O. Halilou and V. Vadez, Assessment of groundnut under combined heat and drought stress, Journal of Agronomy and Crop Science 199 (2013) (1) 1-11, doi: https://doi.org/10.1111/j.1439-037X.2012.00518.x.

[9] D. K. Okello, M. Biruma and C. M. Deom, Overview of groundnuts research in Uganda: Past, present and future, Academic Journals 9 (2010) (39) 6448-6459.

[10] M. Balota, Effects of drought and heat on peanut (Arachishypogaea, L.) production, available online at: https://pubs.ext.vt.edu/AREC/AREC-27/AREC-27NP-pd f.pdf.

[11] H. R. Wotton and R. N. Strange, Increased susceptibility and reduced phytoalexin accumulation in drought-stressed peanut kernels challenged with Aspergillus flavus, Applied and Environmental Microbiology 53 (1987) (2) 270-273.

[12] B. Horn and J. Dorner, Soil populations of aspergillus species from section flavi along a transect through peanut-growing regions of the United States, Mycologia 90 (1998) (5)767-776, doi: 10.237/3761317.

[13] J. I. Pitt, A. D. Hocking and D. R. Glenn, An improved medium for detection of Aspergillus flavus and A. parasiticus, J. Appl. Bacteriol. 54 (1983) 109-114.

[14] A. Arunyanark, S. Jogloy, S.Wongkaew, C. Akkasaeng, N. Vorasoot, G. C. Wright, and A. Patanothai, Association between aflatoxin contamination and drought tolerance traits in peanut, Field Crops Research 114 (2009) 14-22, doi: https://doi.org/10.1016/j.fcr.2009.06.018.

[15] C. Pratiwi, W. P. Rahayu, H. N. Lioe, D. Herawati, W. Broto and S. Ambarwati, The effect of temperature and relative humidity for Aspergillus flavus BIO 2237 growth and aflatoxin production on soybeans, International Food Research Journal 22 (2015) (1) 82-87.

[16] B. W. Horn, Ecology and population biology of aflatoxigenic fungi in soil, Journal of Toxicology 22 (2003) (2-3) 351-379, doi: https://doi.org/10.1081/TXR-120024098.

[17] A. M. Hussaini, A. G. Timothy, H. A. Olufunmilayo, A. S. Ezekiel and H. O. Godwin, Fungi and some mycotoxins found in mouldy sorghum in Niger State, Nigeria, World Journal of Agricultural Sciences 5 (2009) (1) 5-17, doi: https://doi.org/ISSN 1817-3047.

[18] B. Guo, Z. Chen, R. D. Lee and B. T. Scully, Drought stress and preharvest aflatoxin contamination in agricultural commodity: Genetics, genomics and proteomics, Journal of Integrative Plant Biology 50 (2008) (10) 1281-1291, doi: https://doi.org/10.1111/j.1744-7909.2008.00739.x.

[19] K. Hell and C. Mutegi, Aflatoxin control and prevention strategies in key crops of Sub-Saharan Africa, Academic Journals 5 (2011). (5) 459-466, doi: https://doi.org/10.5897/AJMR10.009.

[20] H. Kebede, H. K. Abbas, D. K. Fisher and N. Bellaloui, Relationship between aflatoxin contamination and physiological responses of corn plants under drought and heat stress, Toxins 4 (2012) 1385-1403, doi: http://doi.org/10.3390/toxins4111385.

[21] E. Diao, H. Dong, H. Hou, Z. Zhang, N. Ji and W. Ma, Factors influencing aflatoxin contamination in before and after harvest peanuts: A review, Journal of Food Research $4 \quad$ (2014) (1) 148-154, doi: https://doi.org/10.5539/jfr.v4n1p148

[22] E. Guchi, Aflatoxin contamination in groundnut (Arachishypogaea L.) caused by aspergillus species in Ethiopia, Journal of Applied and Environmental Microbiology 3 (2015) (1) 11-19.

[23] J. Aminifar, M. M. Nik and A. Sirousmehr, Grain yield improvement of groundnut (Arachishypogaea L.) under drought stress conditions, International Journal of Agriculture and Crop Sciences 6 (2013) (12) 819-824.

[24] D. M. Kambiranda, H. K. N. Vasanthaiah, R. K. A. Ananga, S. M. Basha and K. Naik, Impact of drought stress on peanut (Arachishypogaea L.) productivity and food safety, in: H. Vasanthaiah \& D. M. Kambiranda (Eds.), Plants and Environment, 2011, pp. 249-272, available online at: http://www.intechopen.com/books/ plants-and-environment/impact-of-drought-stress-on-pea nut-arachis-hypogaea-1-productivity-and-food-safety.

[25] N. Vorasoot, P. Songsri, C. Akkasaeng, S. Jogloy and A. Patanothai, Effect of water stress on yield and agronomic characters of peanut (Arachishypogaea L.), Songklanakarin J. Sci. Technol. 25 (2003) (3) 31-36. 

Aspergillus flavus Population in the Soil

[26] P. Q. Craufurd, P. V. V. Prasad, F. Waliyar and A. Taheri, Drought, pod yield, pre-harvest Aspergillus infection and aflatoxin contamination on peanut in Niger, Field Crops Research $98 \quad$ (2006) 20-29, doi: https://doi.org/10.1016/j.fcr.2005.12.001.

[27] M. A. Pervez, C. M. Ayub, H. A. Khan, M. A. Shahid and I. Ashraf, Effect of drought stress on growth, yield and seed quality of tomato (Lycopersiconesculentum L.), Pak. J. Agri. Sci. 46 (2009) (3) 174-178.
[28] P. V. V. Prasad, S. A. Staggenborg and Z. Ristic, Impacts of Drought and/or Heat Stress on Physiological, Developmental, growth, and yield processes of crop plants, in: D. Drexler (Ed.), Response of Crops to Limited Water: Understanding and Modeling Water Stress Effects on Plant Growth Processes - Advances in Agricultural Systems Modeling, Series 1, 2008, pp. 301-356. 